\title{
Perspectiva del Ejercicio Profesional del Terapeuta Ocupacional en el Área Educativa
}

Martha Tobón de Awad*

\section{Ponencia presentada el Día del Terapeuta Ocupacional al celebrarse los 25 años de la Asociación Colombiana de Terapia Ocupacional}

La perspectiva del terapeuta ocupacional en el área educativa, es ser parte de la escuela. Y esta propuesta es fácil de realizar gracias a los cambios que se han producido en el campo educativo y a nivel de la intervención de Terapia Ocupacional en el área.

En el campo educativo se han venido produciendo cambios importantes que son el resultado de la influencia de la Constitución Política de 1991, la cual abrió espacios de participación en todos los ámbitos del país. Los cambios más notables son producto de la Ley General de Educación (Ley 115 de 1994), la cual permitió cambiar de manera dramática el antiguo modelo con que habían sido educados los Colombianos. Ese modelo de origen español que se caracterizaba por:

- Programas rígidos decididos por un grupo de expertos del Ministerio de Educación.

- Ambiente educativo basado en el Deber de hacer las cosas ante el temor de ser castigado con malas notas.

- Eje de desarrollo humano alrededor del Conocimiento.

* Terapeuta Ocupacional. Universidad Nacional de Colombia. Por un Mañana. 
- Tendencia a la Homogenización de los estudiantes de todos los colegios.

- Sistema de motivación a partir de premios y castigos.

La Ley General de Educación planteó un camino nuevo cuyos cambios más importantes son:

- Creación de Proyectos Educativos Institucionales que favorecen la creación de programas en cada colegio.

- Ambiente educativo basado en la libertad y el amor.

- Eje de Desarrollo humano a partir del conocimiento y el crecimiento personal.

- Búsqueda del respeto de la individualidad en todos los colegios.

- Cambio del sistema de Calificación: las notas numéricas están dando paso a los indicadores de logros.

- Sistema de motivación a partir de la satisfacción personal.

En forma paralela a la evolución del área educativa, se fueron dando cambios en el quehacer del Terapeuta Ocupacional que venía trabajando con escolares, dándonos otro horizonte que mostrara concordancia con los cambios del modelo educativo:

- Antes se planteaban objetivos de remediación para los niños que presentaban dificultades, diferencias o diferentes ritmos para aprender, con el fin de que funcionaran de acuerdo con lo que el colegio proponía. El énfasis del terapeuta se dirigía más a las exigencias escolares y no al desarrollo individual y estilo personal del niño.

- A partir del 91 el foco de la intervención empezó a transformarse, planteando mas bien objetivos de detección, atención temprana e integración del niño al medio escolar. Y el énfasis del Terapeuta Ocupacional se hizo a partir del respeto de sus diferencias, sin la intención de homologarlo al modelo de alumno del colegio.

- Y actualmente está tomando fuerza el trabajo con objetivos de atención primaria (promoción de la salud) dentro de la escuela, dirigidos a todos los niños y no sólo a aquellos con necesidades especiales. 
La ley 115 de 1994 también hizo lineamientos en otras áreas que tiene que ver con nuestro ejercicio profesional, las cuales nos dan claras directrices de acción para ejercer nuestra profesión dentro de la escuela.

A continuación citaré los artículos y su relación con nuestro trabajo como terapeutas ocupacionales en educación:

- El artículo 13 (página 9 de la Ley 115) que habla de los objetivos comunes a todos los niveles educativos dice:

"Es objetivo primordial de todos y cada uno de los niveles educativos el desarrollo integral de los educandos mediante acciones estructuradas encaminadas a......f) Desarrollar acciones de orientación escolar, profesional y ocupacional.....".

El artículo hace clara referencia a la consultoría de Terapia Ocupacional y orientación profesional.

- El artículo 16 (página 12 de la Ley 115) que plantea los objetivos específicos de la educación preescolar dice:

"Son objetivos específicos del nivel preescolar: a) el conocimiento del propio cuerpo y sus posibilidades de acción....b) El crecimiento armónico y equilibrado del niño, de tal manera que se facilite la motricidad, el aprestamiento y la motivación ......c) El desarrollo de la creatividad, las habilidades y destrezas propias de la edad, como también su capacidad de aprendizaje..... El desarrollo de la capacidad de adquirir formas de expresión, relación y comunicación...f) La participación en actividades lúdicas con otros niños y adultos...

Y se ha reglamentado ya las estrategias para cumplir esta parte de la ley en el decreto número 2247 de 1997 cuyo artículo 12 hace énfasis en el desarrollo de los curriculos a través de proyectos lúdico-pedagógicos cuyo fin básico sea el goce y el juego.

Este artículo plantea la necesidad de que existan terapeutas ocupacionales en los jardines infantiles promoviendo el desempeño ocupacional de los niños preescolares. 
- El artículo 46 (página31 de la Lè̃ 115) plantea la integración de personas con discapacidades:

"La educación para personas con limitaciones físicas, sensoriales, psíquicas, congoscitivas, emocionales o con capacidades intelectuales excepcionales, es parte integrante del servicio público educativo. Los establecimientos educativos organizarán directamente o mediante convenio, acciones pedagógicas o terapeuticas que permitan el proceso de integración académica y social de dichos educandos".

Este artículo plantea la necesidad de que existan equipos terapeuticos dentro de los colegios o asociados a ellos, los cuales favorezcan la integración de los discapacitados y las personas con necesidades especiales.

- El artículo 51 (página 34 de la Ley 115) en la reglamentación de la educación para adultos dice:

“...d) Se debe desarrollar la capacidad de participación en la vida económica, política, social; cultural y comunitaria.

Este artículo plantea la necesidad de que terapeutas ocupacionales trabajen el desempeño ocupacional de las personas dentro de los colegios que alfabetizan adultos.

- El artículo 68 (página 42 de la Ley 115) en lo relacionado con la educación para la rehabilitación social dice:

"La educación para la rehabilitación social comprende los programas educativos que se ofrecen a personas y grupos cuyo comportamiento individual y social exige procesos educativos integrales que les permitan su reincorporación a la sociedad".

Este artículo plantea la necesidad de que los terapeutas ocupacionales formen parte de los equipos de rehabilitación y educación que favorecen la reincorporación de las personas a la sociedad.

Con este panorama planteado por la Ley General de Educación, tenemos un trabajo muy importante por delante: 


\section{"Influir el ambiente de la escuela con nuestro saber para facilitar el cumplimiento de la ley, formando parte del equipo interdis- ciplinario, ya sea dentro o fuera de la escuela".}

Somos el talento humano que puede facilitar el desempeño ocupacional de las personas como se propone en la ley y podemos ayudarle al individuo a enfrentar las exigencias que plantea el aprendizaje.

El rol del Terapeuta Ocupacional en el área educativa se articula con la escuela, a través de la Consultoría escolar. Esta asesoría se puede hacer teniendo en cuenta dos dimensiones: nuestro quehacer y el entorno donde se desempeña el individuo:

- Nuestro quehacer permite proponer una oferta integral que debe partir de un cambio en:

- El enfoque de tratamiento del contexto biomédico hacia el biosocial.

- El sitio de intervención, al pasar del consultorio al espacio escolar y formar parte del equipo de la escuela al lado de padres y maestros.

- La propuesta de intervención para hacerla dentro del contexto escolar donde se mueve el individuo.

- Los objetivos de la intervención, los cuales deben ser acordados con el estudiante, la familia y el maestro para que sean reales, alcanzables y de acuerdo con necesidades inmediatas y sentidas del individuo.

- Nuestra intervención se debe dirigir también al ambiente o Ecología escolar, influyendo el contexto en que se desempeña quien aprende, a través de:

- La capacitación de padres y maestros para la comprensión de las necesidades, fortalezas y debilidades del estudiante.

- La preparación de ambientes estimulantes, facilitádores y remediadores.

- El apoyo a padres y maestros con planes caseros y escolares.

- La ubicación del estudiante en un nivel de enseñanza acorde con sus capacidades, necesidades y estilo cognitivo.

- El establecimiento de exigencias escolares de acuerdo con las capacidades del alumno, por medio del análisis de las actividades a realizar sus demandas, los materiales utilizados, la posición, etc. 
- El cambio de actitud del estudiante, al darle la opción de desarrollar un rol escolar más adecuado a las exigencias del medio, el cual se basa en sus fortalezas y permite el manejo de sus carencias. Ejemplos de acciones puntuales para ejercer nuestro quehacer $e$ influir el entorno son:

- Trabajar por lograr la existencia y el respeto a la diferencia, a través de la participación del equipo de apoyo pedagógico, buscando romper barreras arquitectónicas, adaptando los materiales de trabajo y utilizando ayudas tecnológicas.

- Ofrecer estrategias de tratamiento, manejo y estimulación de los niños que presentan dificultades de aprendizaje para que puedan funcionar en forma adecuada dentro de su grupo escolar.

- Favorecer la creación de proyectos educativos que incluyan estrategias para el juego, el desarrollo sensoriomotor, el desarrollo de la autoestima, la orientación vocacional y el desarrollo de habilidades de ejecución.

- Proponer estrategias para favorecer el aprendizaje de cada niño de acuerdo con su estilo cognitivo más fuerte -visual, auditivo, motriz, tactil.

- Facilitar el desarrollo de los roles propios de la vida escolar por medio de pedagogías como la de la Ternura o, la de la Ecología Humana. Estas orientaciones basadas en la persona, permitirán la existencia de la individualidad y el desarrollo de ritmos personales de aprendizaje.

- Participar en la creación de instrumentos de evaluación y seguimiento de los logros de aprendizaje de los estudiantes, basados en escalas reales de desarrollo, indicadores de adquisición de destrezas y muestras de la forma como el estudiante se ha adueñado del conocimiento.

Finalmente, quiero hacer énfasis en que el campo de desempeño del Terapeuta Ocupacional en el área educativa es amplio, variado y claro. Que está definido por la Ley General de Educación. Y que está en nuestras manos posicionarnos como profesionales indispensables en el equipo interdisciplinario de la escuela. 


\section{BIBLIOGRAFÍA}

Ministerio de Educación Nacional. República de Colombia. Ley General de Educación, Ley 115 de 1994. Empresa Editorial Universidad Nacional. Santa Fe de Bogotá.

Integración Educativa, lineamientos generales. Santa Fe de Bogotá. 1991.

Bissell, Julie. J. Fisher, C. Owens, P. Polcyn (1993). Understanding sensory and motor challenges in the classroom. Sensory Integration International. Torrance Ca. USA.

Bembow, Mary. (1992). Handwriting in the classroom: improvinn writing comunication. AOTA. Self - studies Series. Charlotte Brasic Editora. Rockville MD. USA.

Brassic, Charlote (1992). Classroom aplications for school - based practice. AOTA. Self - studies Series. Charlotte Brasic Editora. Rockville MD. USA. 